\title{
Heritability and Y-chromosome influence in the jack male life history of chinook salmon (Oncorhynchus tshawytscha)
}

\author{
DD Heath ${ }^{1}$, L Rankin², CA Bryden ${ }^{2,4}$, JW Heath ${ }^{3}$ and JM Shrimpton ${ }^{2}$ \\ ${ }^{1}$ Great Lakes Institute for Environmental Research, and the Department of Biological Sciences, University of Windsor, 401 Sunset \\ Ave, Windsor, Ontario, Canada, N9B 3P4; ${ }^{2}$ Biology, College of Science and Management, University of Northern British Columbia, \\ 3333 University Way, Prince George, BC, Canada, V2N 4Z9; ${ }^{3}$ Yellow Island Aquaculture Ltd, 1681 Brook Crescent, Campbell \\ River, BC, Canada, V9W 6 K9
}

\begin{abstract}
Jacking in chinook salmon (Oncorhynchus tshawytscha) is an alternative reproductive strategy in which males sexually mature at least 1 year before other members of their year class. We characterize the genetic component of this reproductive strategy using two approaches; hormonal phenotypic sex manipulation, and a half-sib breeding experiment. We 'masculinized' chinook salmon larvae with testosterone, reared them to first maturation, identified jacks and immature males based on phenotype, and genotyped all fish as male (' $X Y$ ') or female (' $X X$ ') using PCR-based Y-chromosome markers. The $X Y$ males had a much higher incidence of jacking than the $X X$ males $(30.8 \%$ vs $9.9 \%)$. There was no difference in body weight, gonad weight, and plasma concentrations of testosterone and $17 \beta$-estradiol between the two jack genotypes, although $X Y$ jacks did have a higher
\end{abstract}

gonadosomatic index (GSI) than $X X$ jacks. In the second experiment, we bred chinook salmon in two modified halfsib mating designs, and scored the number of jacks and immature fish at first maturation. Heritability of jacking was estimated using two ANOVA models: dams nested within sires, and sires nested within dams with one-half of the halfsib families common to the two models. The sire component of the additive genetic variance yielded a high heritability estimate and was significantly higher than the dam component $\left(h_{\text {sire }}^{2}=0.62 \pm 0.21 ; h_{\mathrm{dam}}^{2}=-0.14 \pm 0.12\right)$. Our experiments both indicated a strong sex-linked component ( $\mathrm{Y}$ chromosome) to jacking in chinook salmon, although evidence for at least some autosomal contribution was also observed.

Heredity (2002) 89, 311-317. doi:10.1038/sj.hdy.6800141

Keywords: sexual maturation; sex manipulation; sex linkage; testosterone; satellite male; maternal effect

\section{Introduction}

Alternative male reproductive strategies have been documented in a wide range of animal taxa (Zimmerer and Kallman, 1989; Roff, 1992; Lank et al, 1995; Gross, 1996). Such alternative strategies may evolve if they have identical mean fitness and thus constitute evolutionarily stable strategies (ESSs) in an evolutionarily stable state (ESSt) (Gross, 1985; Leonardsson and Lundberg, 1986; Ryan et al, 1992; Taborsky, 1998, 2001). The alternative is a conditional strategy where individuals are forced to 'make the best of a bad situation' to maximize their fitness potential (Roff, 1992; Taborsky, 2001). The two approaches differ fundamentally in terms of the genetic component to the reproductive strategy: an ESSt involves individuals with different genetic (heritable) components, while a conditional ESS is determined by environmental variation, and generally is not assumed to have a direct

Correspondence: D Heath, Great Lakes Institute for Environmental Research and the Department of Biological Sciences, University of Windsor, 401 Sunset Ave, Windsor, Ontario, Canada, N9B 3P4. E-mail: dheath@uwindsor.ca

${ }^{4}$ Present Address: AXYS Environmental Consulting Ltd, 2045 Mills Rd West, Sidney, BC, Canada, V8L 3S8

Received 27 September 2001; accepted 14 June 2002 genetic component (Leonardsson and Lundberg, 1986; Chan and Ribbink, 1990; Roff, 1992; Ryan et al, 1992; Hutchings and Myers, 1994; Gross, 1996; but see Gross and Repka, 1998). Surprisingly, few of the numerous published reports of alternative male reproductive strategies provide genetic data (Lank et al, 1995; Taborsky, 2001), despite the potentially pivotal role a genetic component could play in the evolution of such strategies.

Alternative male reproductive strategies are very common in fish (see Roff, 1992; Taborsky, 1998). One example is precocious sexual maturation ('jacking') in male Pacific salmon (Gross, 1991; Heath et al, 1991; Foote et al, 1997; Healey and Prince, 1998). Chinook salmon, Oncorhynchus tshawytscha, spawn in fresh water where the juveniles rear for 6-18 months before migrating to the ocean. Sexually mature fish return to their natal streams to reproduce 1 to 7 years later (Hard et al, 1985; Healey, 1991). Male chinook salmon may exhibit an alternative reproductive strategy and return to reproduce at least 1 year before other fish in their age class (ie, precocious sexual maturation). The incidence of 'jacking' in chinook salmon ranges from $10 \%$ to over $90 \%$ among populations (Hard et al, 1985; Healey, 1991; Heath et al, 1991; DD Heath, unpublished data). Jacks are characterized by reduced or absent secondary sexual characteristics, small body size, and mating behavioral differences (ie, 'sneak' mating; 
Gross, 1985; Healey and Prince, 1998). Jacking has been successfully modeled as an ESS in coho salmon (Gross, 1985; Roff, 1992), but one of the fundamental assumptions of such models is the presence of a genetic component to the trait (Gross, 1985; Leonardsson and Lundberg, 1986; Hutchings and Myers, 1994). More recently, conditional ESS models for alternative male reproductive strategies in salmonids have been proposed that do not assume a direct genetic component (Gross, 1996; Foote et al, 1997).

There have been a few reports on the genetic nature of alternative male reproductive strategies in fish (eg, Naevdal, 1983; Taborsky, 2001). Interestingly, an appreciable number of the studies identified some level of sexlinkage contributing to the strategies (Kallman et al, 1973; Kallman, 1983; Zimmerer and Kallman, 1989; ErbeldingDenk et al, 1994, but see Kolluru and Reznick, 1996). In Pacific salmon (Oncorhynchus spp.), only a handful of published studies have examined the genetic component to jacking, although an analogous phenomenon ('grilsing') in Atlantic salmon, Salmo salar, has been better characterized (eg, Naevdal, 1983; Gjerde, 1984). Iwamoto et al (1984) reported a significant sire effect on jacking in coho salmon, Oncorhynchus kisutch, while an additive genetic component to jacking in chinook salmon has been demonstrated using both traditional breeding and molecular genetic methods (Heath et al, 1994a, 1994b; Mousseau et al, 1998). None of those studies were designed to detect possible sex-linkage, although Heath et al, (1994a) did speculate on this possibility in chinook salmon.

We describe here two experiments designed to test whether jacking in chinook salmon is male sex-linked ( $\mathrm{Y}$ chromosome linkage) and to estimate the heritability of the trait. The first experiment involved rearing phenotypic males that were genotypically either male or female (ie, $X Y$ or $X X)$, to first sexual maturation and then comparing jacking rates between the two genotypes. The second experiment consisted of a modified half-sib breeding experiment (54 families) designed to estimate male and female additive genetic components for jacking. If jacking in chinook salmon has a Y-linked component we would expect to observe higher sire-based additive genetic variance for the jacking trait; furthermore, Y-linkage may also lead to increased jacking rates in $X Y$ genotype fish. If both effects were observed, it would represent strong independent lines of evidence for Y-linkage and would thus have important implications for the interpretation of the evolution of alternative male reproductive strategies in salmonids.

\section{Materials and methods}

\section{Experiment 1 (hormonal sex manipulation)}

Four sexually mature 3-year-old female and four sexually mature 2-year-old male ('jack') chinook salmon were randomly selected from broodstock held at Yellow Island Aquaculture Ltd (YIAL), a commercial salmon farm near Campbell River on Vancouver Island, BC. The fish were spawned on 26 October 1995 and the eggs from each female were fertilized with milt from one of the males in a one-to-one breeding design. All fertilized eggs were combined and incubated at $10^{\circ} \mathrm{C}$ in a vertical-stack incubation tray. The four families were used because of known large variation in jacking rate among families
(Heath et al, 1994a), and to protect against possible whole-family loss. Blood samples were taken from all parents for later DNA extraction and analysis. Developmental stage in juvenile salmonids is typically quantified as the number of accumulated temperature units (ATUs). Surviving eggs were counted at approximately 250 ATUs and approximately 4000 live eggs were retained (1000 from each family). All fish used in this study were masculinized using a modification of the protocol described by Hunter et al (1983). Briefly, the newly hatched larvae were immersed in a re-circulating, oxygenated bath treatment of $17 \alpha$-methyltestosterone $(400 \mu \mathrm{g} / \mathrm{L})$ for $2 \mathrm{~h}$. The bath treatment was applied twice, once at 520 ATUs and a second treatment at 620 ATUs. We did not apply the suggested feed treatment due to unacceptably high levels of sterility observed in previous trials; the modified protocol has been found to masculinize approximately $60-80 \%$ of female chinook salmon (DD Heath, unpublished data). Larvae were reared at $10^{\circ} \mathrm{C}$ in the incubation tray until they began exogenous feeding, after which they were reared in a $3000 \mathrm{~L}$ tank at $10^{\circ} \mathrm{C}$. Fish were transferred to a $1000 \mathrm{~m}^{3}$ seacage on 17 June 1996, and reared following standard commercial rearing protocols.

In September 1997, the experimental fish were sorted into sexually mature and immature groups based on secondary sexual characteristics. Within captive chinook salmon populations, jacks are typically larger than non-maturing fish (but smaller than older sexually mature fish), and also have darker skin color (Heath et al, 1991). All of the sexually mature fish $(n=267)$ were euthanized and a blood sample taken. The first 204 immature fish collected were also euthanized and sampled for blood. The blood was centrifuged and the plasma and packed blood cells were separated and frozen $\left(-30^{\circ} \mathrm{C}\right)$ for subsequent hormonal and DNA analysis. All euthanized fish were dissected and the gonads inspected and weighed to determine phenotypic sex and confirm maturation status. The remaining immature fish $(n=1261)$ were counted and a fin clip was taken and stored in ethanol for DNA analysis.

Genotypic sex was determined using the PCR-based Ychromosomal markers described by Devlin et al, (1991, 1994) and Du et al, (1993). DNA was extracted from the blood samples from the parent fish $(n=8)$ and all euthanized offspring fish $(n=471)$, and from the fin clips taken from remaining offspring fish $(n=1261)$, using a standard proteinase $\mathrm{K}$ digestion method (Devlin et al, 1991). The first round of PCR genotype sex testing used published primer sequences (Devlin et al, 1994) and a standard thermal cycler protocol $\left(1 \mathrm{~min} \times 94^{\circ} \mathrm{C}\right.$ denature cycle, $1 \mathrm{~min}$ $\times 52^{\circ} \mathrm{C}$ annealing cycle, and $45 \mathrm{sec} \times 72^{\circ} \mathrm{C}$ extension cycle) for 35 cycles. Reactions contained $1 \mu \mathrm{l}$ of the extracted DNA, $0.5 \mu \mathrm{l}$ of each primer $(100 \mathrm{ng} / \mu \mathrm{l}), 2.5 \mu \mathrm{l}$ of the $10 \times$ reaction buffer (Gibco-BRL), $1.5 \mu \mathrm{l}$ of $25 \mathrm{mM} \mathrm{MgCl}_{2}, 1.0$ $\mathrm{U}$ Taq polymerase (Gibco-BRL), and $\mathrm{ddH}_{2} \mathrm{O}$ to make up a $25 \mu$ volume. All PCRs were visualized on $1.8 \%$ agarose gels stained with ethidium bromide. Fish were classified as either genotypic males ( $\left.X Y^{\prime}\right)$ or genotypic females (' $\left.X X^{\prime}\right)$ based on the presence or absence of a $Y$ specific $209 \mathrm{bp}$ fragment (Devlin et al, 1994). This determination was made without reference to phenotypic sex. All fish that were judged to have ambiguous fragment size patterns were run a second time to confirm genetic sex using the Y-specific PCR sex probe described in Du et al, 
(1993). Parental fish were independently genotyped three times with each marker.

Plasma concentrations of testosterone and 17 $\beta$-estradiol were measured for 69 of the jacks (35 XX; $34 \mathrm{XY}$ ), and for 65 of the immature fish (32 XX; $33 \mathrm{XY})$. These assays were included to test for phenotypic differences between the $X X$ and $X Y$ males. Fish in these subsamples were chosen to reflect the observed range of body weights in the full sample (subsample mean weight did not differ from full sample, $P>0.15$ ). Plasma testosterone and $17 \beta$-estradiol concentrations were determined using commercially available competitive-binding radioimmunoassays (DiaSorin, Stillwater, MN, USA). The sensitivity of the estradiol RIA is below $5 \mathrm{pg} / \mathrm{mL}$ and below 0.06 $\mathrm{ng} / \mathrm{mL}$ for the testosterone assay. The estradiol assay has no significant cross-reactivity $(<1 \%)$, while the testosterone assay has an approximately $10 \%$ cross-reactivity with nortestosterone.

Since the jacking rate in the $X X$ fish is dependent on the number of XX fish that have been successfully masculinized, we determined the frequency of masculinization in the XX fish within the euthanized group. We then calculated the number of masculinized $X X$ fish in the noneuthanized group by multiplying the number of $X X$ fish by the frequency of masculinization in the XX fish. Differences in overall maturation rate ('jacking rate') for the $X X$ and $X Y$ fish were tested using Pearson's chi-square analysis. Differences between $X X$ and $X Y$ genotype fish in total weight, gonad weight, gonadosomatic index (GSI $=[$ gonad weight $/$ total weight $] \times 100 \%)$, testosterone, and estradiol were tested within jacks and immature fish using one-way ANOVA. Total weight differences between jacks and immature fish were also tested using one-way ANOVA.

\section{Experiment 2 (breeding experiment)}

Seventy-six parent fish (38 sires, 38 dams) were artificially spawned on 23 October 1997 at YIAL. Half of the parental fish were from YIAL stock, the other half were from the Big Qualicum River stock. All parental fish were aged 3 years (based on body size only for the Big Qualicum stock), ie no jack sires were used. A replicated partial diallel-cross mating design ( 2 sires $\times 2$ dams $)$ was used to generate a total of 76 crosses ('families'). Families were reared in separate incubation compartments and transferred to 200 L rearing tanks 29-30 January 1998. Fry were maintained indoors under dim artificial light (initially $10 \mathrm{~h}$ light: $14 \mathrm{~h}$ dark, increasing to $15 \mathrm{~h}$ light: 9 $\mathrm{h}$ dark by late April) and hand-fed commercial feed multiple times per day.

Fish were nose-tagged with an automatic tagging unit (Northwest Marine Technology, Shaw Island, WA, USA) in May, 1998. The nose-tags were colour coded with each family assigned a unique code. The fish were subsequently transferred to YIAL's saltwater holding facilities on 6 July 1998 (256 days post-fertilization). All families were housed together in a $500 \mathrm{~m}^{3}$ seacage until 6 January 1999 when they were transferred to a full-size seacage $\left(1000 \mathrm{~m}^{3}\right)$ where they remained for the rest of the study. Fish were hand-fed to satiation with commercial feed twice per day.

In July 1999 (approximately 20 months post fertilization) a random sample of 742 fish was euthanized and their nose tags recovered and de-coded. In September 1999, all surviving fish were counted and sorted into mature (jacks) and immature groups. All jacks were euthanised and their nose tags retrieved and decoded. The number of jacks within each family was determined by direct count. The number of immature fish in each family was estimated by multiplying the proportion of immature fish in each family (based on the 742 sampled fish) by the total number of immature fish in the experiment $(n=1653)$.

Heritability was calculated using the threshold trait analysis described in Roff (1997): jack vs non-jack (immature) phenotype was scored as 0 and 1, and ANOVA was used to estimate mean squares. Two models were used, one with dams nested within sires for an estimate of $\sigma_{\text {sire }}^{2}$ and one with sires nested within dams for an estimate of $\sigma_{\text {dam }}^{2}$. Both sire and dam were random effects within the model, and analyses were performed using SYSTAT version 7.0.1 (SPSS 1997 Inc). A subset of the available families were used for heritability estimation to avoid having half-sib families present across nested groups (36 full-sib families for both the dam nested within sire model and for the sire nested within dam model with 18 full-sib families in common). We refer to our design as an overlapping nested model, since half of the full-sib families were included in both the ANOVA models (total number of families = 54). We chose the non-nested parent (either sire or dam) to be YIAL stock, since YIAL stock was used for Experiment 1. Estimates of heritability were corrected for liability scale and standard errors were calculated following Roff (1997).

\section{Results}

\section{Experiment 1 (hormonal sex manipulation)}

The female parental fish were found to have the XX genotype using both markers in all replicates. Three of the four male parents were found to have the XY genotype for both markers in all replicates. One putative male parent was found to have an ambiguous genotype using the first marker (Devlin et al, 1994), but was found to have an unambiguous $\mathrm{XX}$ genotype using the second marker (Du et al, 1993). Closer inspection of the results from the first marker for this fish showed the absence of the malediagnostic $209 \mathrm{bp}$ fragment, indicating that this male parent was genotypically female. The origin of this anomalous parental fish is likely to have been production stock used at our collaborators' commercial salmon farm site where masculinized female fish are used as broodstock.

The jacking rate for the masculinized XX fish was $9.9 \%$, while $30.8 \%$ of the XY fish jacked (Table 1). The jacking

Table 1 Categories of chinook salmon offspring from Experiment 1 (hormonal sex manipulation) by genotypic sex (XX and $X Y$ ) and by maturation status (jacks and immature fish)

\begin{tabular}{lccccc}
\hline & \multicolumn{2}{c}{ Male phenotype } & \multicolumn{2}{c}{$\begin{array}{c}\text { Female } \\
\text { phenotype }\end{array}$} & Total \\
\cline { 2 - 4 } & \multicolumn{2}{c}{ Mature - Jack } & Immature & & \\
\hline $\begin{array}{l}\text { Genotypic females } \\
(X X)\end{array}$ & 83 & 749 & 306 & 1138 \\
$\begin{array}{l}\text { Genotypic males } \\
(X Y)\end{array}$ & 184 & 410 & - & 594 \\
\hline
\end{tabular}


rate for the $X Y$ males was significantly higher than for the $\mathrm{XX}$ males $(P<0.0001)$. The overall genotypic sex ratio of the study fish was 65:35 females to males (1138 XX, 594 XY; Table 1). The masculinization rate for the XX fish (not including jacks) was estimated to be $71 \%$ (114 of 161 XX immature fish had the male phenotype). Thus, the total estimated number of masculinized XX fish (not including jacks) was 749 (71\% of 1055), with 306 fish (29\% of 1055) estimated to have the female phenotype (Table 1).

The $X X$ jacks were larger than the $X Y$ jacks, but the difference was not significant $(P>0.05$; Figure 1a), nor was there a significant difference in weight between the $X X$ and $X Y$ immature groups $(P>0.10$; Figure 1a). Previous work has shown that jacks have significantly larger body size than immature fish in the same cohort (Heath et al, 1991), our data showed a similar pattern (XX and $X Y$ jacks were significantly heavier than immature males; $P<0.001 ;$ Figure 1a). There were no significant differ-
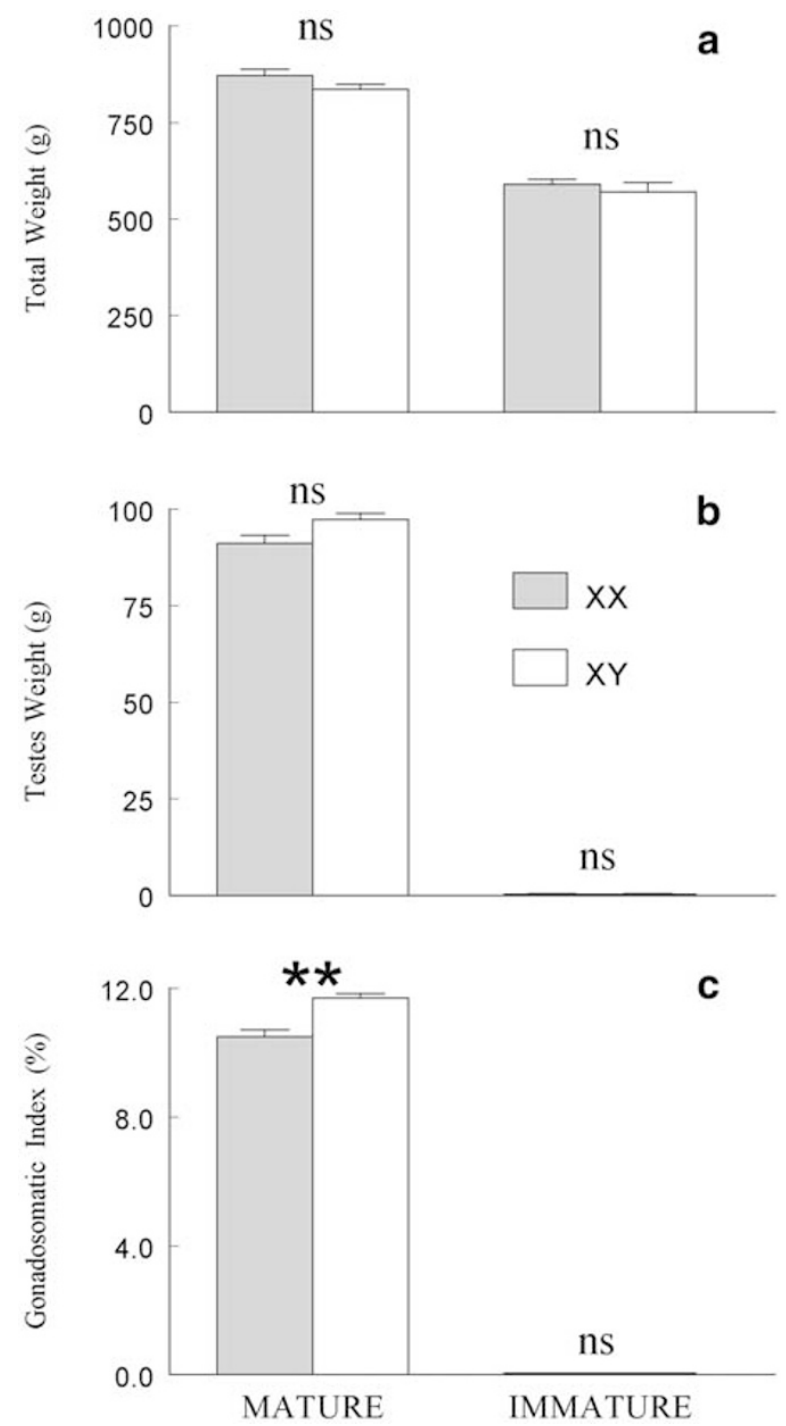

Figure 1 Physical measurements on four classes of chinook salmon; sexually mature (jack) $X X$ and $X Y$ males and immature $X X$ and $X Y$ males. Measurements include; (a) total weight, (b) testes weight, and (c) Gonodosomatic index (ratio of testes to total weight). Error bars represent $1 \mathrm{SE}$, and ns $=$ not significant $(P>0.05),{ }^{* *} P<0.01$. ences between the $X X$ and $X Y$ males in either maturation group for testes weight $(P>0.10$; Figure $1 b)$. The $X Y$ jacks had a significantly higher GSI than the XX jacks $(P$ $<0.01$; Figure 1c); the mean GSI of the XX jacks was 10.5 \pm 0.21 ( $\pm 1 \mathrm{SE}$ ), while the $X Y$ jack mean GSI was $11.7 \pm$ 0.14 . There was no significant difference in GSI between the immature $X X$ and $X Y$ males (Figure 1c).

Mature fish had greatly elevated levels of plasma testosterone and estradiol. The mean plasma concentration of estradiol for the XX jacks was $0.095 \pm 0.006 \mathrm{ng} / \mathrm{ml}$, and $0.112 \pm 0.009 \mathrm{ng} / \mathrm{ml}$ for the $X Y$ jacks. Estradiol was very low in immature $X X$ and $X Y$ males $(0.003 \pm 0.001 \mathrm{ng} / \mathrm{ml}$ and $0.006 \pm 0.001 \mathrm{ng} / \mathrm{ml}$, respectively). The mean plasma concentration of testosterone for the XX jacks was $10.8 \pm$ $1.1 \mathrm{ng} / \mathrm{ml}$, and $11.3 \pm 1.1 \mathrm{ng} / \mathrm{ml}$ for the $X Y$ jacks. Testosterone was also low in the non-mature $\mathrm{XX}$ and $\mathrm{XY}$ males $(0.44 \pm 0.22 \mathrm{ng} / \mathrm{ml}$ and $0.73 \pm 0.46 \mathrm{ng} / \mathrm{ml}$, respectively). There were no significant differences between the $X X$ and $X Y$ males within either the mature (jack) or immature groups for testosterone or estradiol $(P>0.10)$.

\section{Experiment 2 (breeding experiment)}

A total of 291 jacks and 1653 immature fish were present at the end of the experiment, for an overall jacking rate of $15.0 \%$. Although these fish were not sex genotyped, they represent offspring from a large number of parental fish taken from YIAL production fish. Previous genotyping data for the YIAL production fish yielded a sex ratio of $48.5 \%$ (Heath et al, 1994a), based on that sex ratio, the estimated male-specific jacking rate is approximately $30 \%$. The jacking rate varied considerably among families (range $0-41 \%$; Figure 2). Sire and dam components in both ANOVA models were highly statistically significant (Table 2). The dams nested within sire model explained $22.2 \%$ of the total variance, while the sires nested within dams model explained $16.5 \%$ of the total variance. Heritability estimates reflected a strong sire bias: $h_{\text {sire }}^{2}=0.62 \pm 0.21 ; h_{\mathrm{dam}}^{2}=-0.14 \pm 0.12$ after correction for the liability scale calculation. Heritability estimates based on the nested terms reflected a similar pattern $\left(h_{\text {sires }}^{2}\right.$ dams $\}=0.68 \pm 0.25 ; h_{\text {dams }}^{2}$ sires $\left.\}=0.12 \pm 0.09\right)$, but interpretation is not straightforward because of confounding environmental, maternal, and dominance effects in the

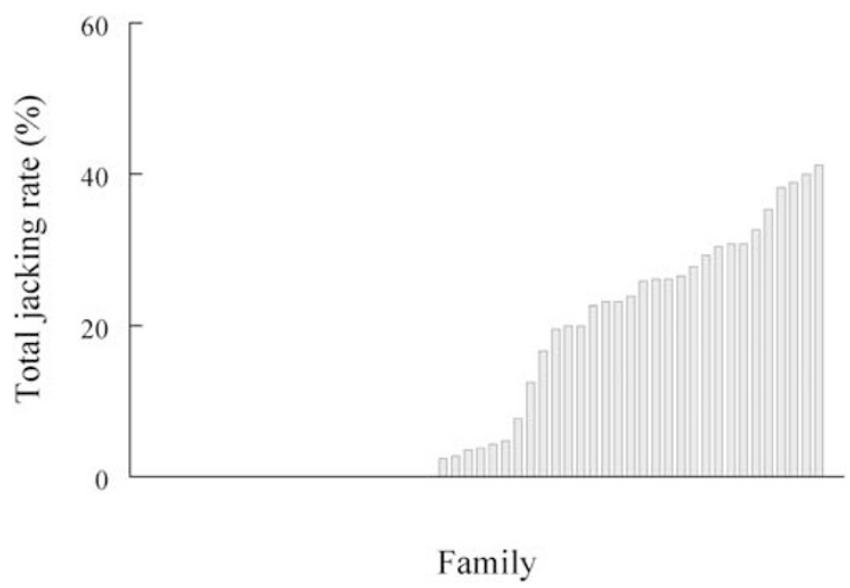

Figure 2 Total jacking rates (percent) for 54 families of chinook salmon used in heritability calculations, arranged in ascending order. Total number of fish per family varied considerably, with a mean total number of $26(9-46)$. 
Table 2 Nested ANOVA results from Experiment 2 (breeding experiment) using two models for sire and dam effects on jacking rates in chinook salmon

\begin{tabular}{|c|c|c|c|c|}
\hline Source & $\begin{array}{l}\text { Sum of } \\
\text { Squares }\end{array}$ & d.f. & Mean-square & $P$ \\
\hline \multicolumn{5}{|c|}{ Dams nested within sires: } \\
\hline SIRE & 11.4 & 17 & 0.673 & $<0.00001$ \\
\hline DAM $\{$ SIRE $\}$ & 2.01 & 18 & 0.114 & 0.04 \\
\hline Error & 53.1 & 906 & 0.059 & \\
\hline \multicolumn{5}{|c|}{ Sires nested within dams: } \\
\hline DAM & 6.6 & 17 & 0.385 & $<0.00001$ \\
\hline SIRE $\{\mathrm{DAM}\}$ & 12.1 & 18 & 0.672 & $<0.00001$ \\
\hline Error & 104.2 & 909 & 0.115 & \\
\hline
\end{tabular}

nested terms (Roff, 1997). All of our heritability estimates are significant, based on Roff's (1997 p 46) recommendation that ANOVA significance should outweigh a confidence interval that encompasses zero for heritability.

\section{Discussion}

Precocious sexual maturation in chinook salmon is found only in male fish (Hard et al, 1985; Healey, 1991; Heath et al, 1991, 1994a). There are two (not mutually exclusive) genetic mechanisms for such an association between phenotypic sex and jacking: (1) jacking genes are present in both sexes, but have male limited expression, and/or (2) jacking genes are sex-linked. The results from our two experiments provide compelling evidence for a sexlinked component to jacking in chinook salmon, although the occurrence of $\mathrm{XX}$ jacks indicates that there must also be an autosomal contribution. Furthermore, quantitative genetic analysis of jacking in chinook salmon indicates at least some autosomal inheritance of the jacking phenotype (Heath et al, 1994a, b; Mousseau et al, 1998), although this study showed no strong evidence for a significant dam additive genetic variance component. Rearing environment (particularly factors affecting growth) also plays a role in determining the incidence of precocious sexual maturation in Pacific salmon (Gross, 1991; Heath et al, 1994a; but see Iwamoto et al, 1984). We thus conclude that jacking in chinook salmon is a polygenic trait that likely follows a threshold model, where the threshold is partially environmentally determined (Hutchings and Myers, 1994; Roff, 1997), or alternatively, the threshold is fixed, but the phenotypic variance varies with environment (Gross, 1996). In either case, the liability scale is determined by multiple loci, some of which are linked with the sex determining region (Y-chromosome).

To our knowledge, no other study has documented any form of sex-linkage for alternative male life histories in salmon. Sex linkage has been documented for alternative male life history strategies in Poeciliids (Kallman et al, 1973; Kallman, 1983; Borowsky, 1987; Zimmerer and Kallman, 1989; but see Kolluru and Reznick, 1996). However, examples from other species indicate that sex-linked genetic control is not the rule for alternative male life history strategies (Shuster and Wade, 1991; Lank et al, 1995; Sluyter et al, 1997; Lank et al, 1999), although male-specific genes are often found on the Y-chromosome in mammals (Nachman, 1998). Interestingly, the expectation for 'randomly' situated genes should include very few examples of $\mathrm{Y}$ chromosome-linkage, even for male-specific traits. The growing number of studies showing Ylinkage for alternative male life history strategies, particularly in fish, support the hypothesis of an adaptive advantage to having genes for male-specific traits reside on the Y-chromosome (Lank et al, 1999). Additive genetic variance is critical for the evolutionary evaluation of alternative male reproductive strategies (Leonardsson and Lundberg, 1986; Chan and Ribbink, 1990; Roff, 1992; Ryan et al, 1992; Hutchings and Myers, 1994; Gross, 1996; but see Gross and Repka, 1998). However, our data indicates that sex-linkage should also be considered, since sex-linked traits are expected to evolve in qualitatively and quantitatively different ways (Nachman, 1998; Wade, 1998; Lank et al, 1999).

Our sire-based heritability estimate is high, and similar to others previously reported (Heath et al, 1994a; Mousseau et al, 1988), while our dam-based heritability estimate was negative and only marginally significant. Our overlapping half-sib design allowed explicit tests for sexlinkage and/or maternal effects. Under the first ANOVA model (dams nested within sires) $\sigma_{\text {sire }}^{2}$ includes only the sire component of the additive genetic variance. However, under the second ANOVA model (sires nested within dams), $\sigma_{\text {dam }}^{2}$ includes additive genetic variance plus maternal effects. Thus, a higher sire versus dam component of the additive genetic variance can result from sex-linked inheritance, negative maternal effects, or a combination of the two. We judge the likelihood of negative maternal effects as a major factor in our analysis is remote, since maternal effects typically decline in magnitude rapidly during the freshwater stage and do not persist beyond one year in chinook salmon (Heath et al, 1999). Nevertheless, the possibility of negative maternal effects confounding our estimate of dam component additive genetic variance cannot be dismissed, especially since we found a negative dam-based heritability.

An assumption made in the interpretation of our sexmanipulation data was that the only difference between the $X Y$ and $X X$ males was the presence/absence of the $Y$ chromosome. This simplistic assumption may not be correct. The effect of the testosterone treatment may differ depending on whether the developing larvae are $X X$ or XY. The masculinization treatment may have acted to exaggerate male traits in the $X Y$ fish, or may have been only partially effective in the female fish (ie, the XX males may lie on an intersex continuum). Although either possibility might lead to higher jacking rates in $X Y$ relative to $\mathrm{XX}$ fish (as well as other phenotypic differences), we feel they are unlikely to be major factors in our experiment. The similarity in circulating testosterone or estradiol in the $X X$ and $X Y$ jacks suggests that no large endocrinological differences exist. Neither did the $X Y$ and $X X$ jacks differ significantly in either body size or gonad weight. Furthermore, if the larval testosterone treatment had resulted in exaggerated male traits (and thus artificially increased jacking incidence), then our experimental jacking rate would be expected to be higher than in untreated $X Y$ fish. This is not the case (male jacking rates in this stock are approximately 30-40\%; this study [Experiment 2]; Heath et al, 1994a). If, on the other hand, the difference in jacking rates was due to the XX males being incompletely masculinized, we would expect these fish to be incapable of normal sexual maturation and gamete production. In fact, masculinized XX fish undergo normal 
phenotypic changes associated with sexual maturation in male salmon, and are fully capable of fertilizing eggs (Hunter et al, 1983; DD Heath, unpublished data). GSI, the only significant phenotypic difference between the two groups, reflects relative energetic allocation to reproduction in male salmon. It is possible that the higher GSI found in $X Y$ jacks (relative to the $X X$ jacks) reflects additional Y-linked genetic factors, and not necessarily treatment-associated effects. Interestingly, the $\mathrm{XY}$ jacks not only had a higher GSI, they also exhibited slightly lower body weight, perhaps the XY jacks allocated more of their somatic resources to gonad production. Our data show a pronounced sex ratio bias (65\% female offspring). This is largely due to our inadvertent use of a genotypic XX male as one of the sires, which changed the expected sex ratio of the offspring to $62.5 \%$ female. Otherwise, the use of a 'female' jack as one of the parents had no direct effect on our results or conclusions.

Gross (1996) argued that understanding the environmental and genetic control of alternative male life history strategies is a key component to predicting the fitness consequences of various strategies. Since sex-linkage will have profound implications for the expected evolution of any life history trait, the potential for such linkage should be assessed via both empirical and theoretical research. Thus, future research should be directed towards determining the chromosomal location and genetic mechanisms behind alternative male reproductive strategies, and sex-specific life history traits in general.

\section{Acknowledgements}

We would like to thank CW Fox, RH Devlin, DA Roff, and TA Mousseau for valuable comments and criticisms of this work. GA Heath, VA Heath, RI Hepburn, and CR Busch were instrumental in much of the field and laboratory work. This work was supported by Yellow Island Aquaculture Ltd., and a Natural Science and Engineering Council (NSERC) of Canada research grant to DDH. LR and $\mathrm{CAB}$ were funded by post-graduate scholarships (GREAT) from the British Columbia Science Council, and an NSERC of Canada post-graduate scholarship to CAB.

\section{References}

Borowsky R (1987). Genetic polymorphism in adult male size in Xiphophorus variatus (Antheriniformes: Poeciliidae). Am Zool 24: 355-366.

Chan TY, Ribbinik AJ (1990). Alternative reproductive behaviour in fishes, with particular reference to Lepomis macrochira and Pseudocrenilabrus philander. Env Biol Fish 28: 249-256.

Devlin RH, McNeil BK, Groves DD, Donaldson EM (1991). Isolation of a Y-chromosomal DNA probe capable of determining genetic sex in chinook salmon (Oncorhynchus tshawytscha). Can J Fish Aquat Sci 48: 1606-1612.

Devlin RH, McNeil BK, Solar II, Donaldson EM (1994). A rapid PCR-based test for Y-chromosomal DNA allows simple production of all-female strains of chinook salmon. Aquaculture 128: 211-220.

Du S, Devlin RH, Hew CL (1993). Genomic structure of growth hormone genes in chinook salmon (Oncorhynchus tshawytscha): presence of two functional genes, GH-I and GH-II, and a male-specific pseudogene, GH- $\Psi$. DNA Cell Biol 12: 739-751.

Erbelding-Denk C, Schroeder JH, Schartl M, Nanda I, Schmid M, Epplin JT (1994). Male polymorphism in Limia perugiae (Piscies: Poeciliidae). Behav Gen 24: 95-101.

Foote CJ, Brown GS, Wood CC (1997). Spawing success of males using alternative mating tactics in sockeye salmon. Oncorhynchus nerka. Can J Fish Aquat Sci 54: 1785-1795.

Gjerde B (1984). Response to individual selection for age at sexual maturity in Atlantic salmon. Aquaculture 38: 229-240.

Gross MR (1985). Disruptive selection for alternative life histories in salmon. Nature 313: 47-48.

Gross MR (1991). Salmon breeding behavior and life history evolution in changing environments. Ecology 72: 1180-1186.

Gross MR (1996). Alternative reproductive strategies and tactics: diversity within sexes. TREE qq: 92-98.

Gross MR, Repka J (1998). Stability with inheritance in the conditional strategy. J Theor Biol 192: 445-453.

Hard JJ, Wertheimer AC, Heard WR, Martin RM (1985). Early male maturity in two stocks of chinook salmon (Oncorhynchus tshawytscha) transplanted to an experimental hatchery in southeastern Alaska. Aquaculture 48: 351-359.

Healey MC (1991). Life history of chinook salmon (Oncorhynchus tshawytscha). In: Groot C (ed) Pacific Salmon Life Histories. UBC Press: Vancouver. pp. 311-394.

Healey MC, Prince A (1998). Alternative tactics in the breeding behaviour of male coho salmon. Behaviour 135: 1099-1124.

Heath DD, Devlin RH, Heath JW, Iwama GK (1994a). Genetic, environmental, and interaction effects on the incidence of jacking in chinook salmon (Oncorhynchus tshawytscha). Heredity 72: 146-154.

Heath DD, Fox CW, Heath JW (1999). Maternal effects on offspring size: variation through early development of chinook salmon. Evolution 53: 1605-1611.

Heath DD, Heath JW, Iwama GK (1991). Maturation in chinook salmon, Oncorhynchus tshawytscha (Walbaum): early identification based on the development of a bimodal weightfrequency distribution. J Fish Biol 39: 565-575.

Heath DD, Iwama GK, Devlin RH (1994b). DNA fingerprinting used to test for family effects on precocious sexual maturation in two populations of Oncorhynchus tshawytscha (chinook salmon). Heredity 73: 616-624.

Hunter GA, Donaldson EM, Stoss J, Baker I (1983). Production of monosex female groups of chinook salmon (Oncorhynchus tshawytscha) by the fertilization of normal ova with sperm from sex-reversed females. Aquaculture 33: 355-364.

Hutchings JA, Myers RA (1994). The evolution of alternative mating strategies in variable environments. Evol Ecol 8: 256268.

Iwamoto RN, Alexander BA, Hershberger WK (1984). Genotypic and environmental effects on the incidence of sexual precocity in coho salmon (Oncorhynchus kisutch). Aquaculture 43: 105121.

Kallman KD (1983). The sex determining mechanism of the Poeciliid fish, Xiphophorus montezumae, and the genetic control of the sexual maturation process and adult size. Copeia 1983: 755-769.

Kallman KD, Schreibman MP, Borkoski V (1973). Genetic control of gonadotrop differentiation in the platyfish, Xiphophorus maculatus (Poeciliidae). Science 181: 678-680.

Kolluru GR, Reznick DN (1996). Genetic and social control of male maturation in Phallichthys quadripunctatus (Pisces: Poeciliidae). J Evol Biol 9: 695-715.

Lank DB, Coupe M, Wynne-Edwards KE (1999). Testosteroneinduced male traits in female ruffs (Philomachus pugnax): Autosomal inheritance and gender differentiation. Proc Roy Soc Lond B 266: 2323-2330.

Lank DB, Smith CM, Hanotte O, Burke T, Cooke F (1995). Genetic polymorphism for alternative mating behaviour in lekking male ruff Philomachus pugnax. Nature 378: 59-62.

Leonardsson K, Lundberg P (1986). The choice of reproductive tactics as a mixed evolutionary stable strategy: the case of male Atlantic salmon (Salmo salar L.). Rep Inst Freshw Res Drottningholm 63: 69-76.

Mousseau TA, Ritland K, Heath DD (1998). A novel method for estimating heritability using molecular markers. Heredity 80: 218-224. 
Nachman MW (1998). Y chromosome variation of mice and men. Mol Biol Evol 15: 1744-1750.

Naevdal G (1983). Genetic factors in connection with age at maturation. Aquaculture 33: 97-106.

Roff DA (1992). The Evolution of Life Histories; theory and analysis. Chapman and Hall: New York.

Roff DA (1997). Evolutionary Quantitative Genetics. Chapman and Hall: New York.

Ryman MJ, Pease CM, Morris MR (1992). A genetic polymorphism in the swordtail Xiphophorus nigrensis: testing the prediction of equal fitness. Am Nat 139: 21-31.

Shuster SM, Wade MJ (1992). Equal mating success among male reproductive strategies in a marine isopod. Nature 350: 608610.
Sluyter F, Bult A, Lynch CB, Meeter F, Vanoortmerssen GA (1997). No evidence for a $Y$ chromosomal effect on alternative behavioral strrategies in mice. Behav Gen 27: 477-482.

Taborsky M (1998). Sperm competition in fish: "bourgeois" males and parasitic spawning. TREE 13: 222-227.

Taborsky M (2001). The evolution of bourgeois, parasitic, and cooperative reproductive behaviours in fishes. J Hered 92: 100-110.

Wade MJ (1998). The evolutionary genetics of maternal effects. In: Mousseau TA, Fox CW (eds) Maternal Effects As Adaptations, Oxford University Press: New York. pp. 5-21.

Zimmerer EJ, Kallman KD (1989). Genetic basis for alternative reproductive tactics in the pygmy swordtail. Xiphophorus nigrensis. Evolution 43: 1298-1307. 